\title{
UNESCO, mulheres e biopoder no Brasil: alguns apontamentos
}

\author{
Flávia Cristina Silveira Lemos, ${ }^{\prime, ~}$ Dolores Cristina Gomes Galindo, II Marilda Castelar, ${ }^{I I I}$ \\ Leandro Passarinho Reis Júnior, I Thais Nogueira, I Pedro Paulo Freire Piani \\ I Universidade Federal do Pará, Belém, PA, Brasil \\ II Universidade Federal de Mato Grosso, Cuiabá, MT, Brasil \\ ${ }^{I I I}$ Escola Bahiana de Medicina e Saúde Pública, Salvador, BA, Brasil
}

\begin{abstract}
Resumo
O texto interroga as práticas da Organização das Nações Unidas para a Educação, a Ciência e a Cultura (UNESCO) frente às mulheres brasileiras e opera uma analítica dos discursos racistas e utilitaristas que promovem disciplina e regulações securitárias com base na educação e cultura. A preocupação com os direitos violados nos países chamados em desenvolvimento pela UNESCO, e seus designados parceiros se, de um lado, constitui um importante anteparo às violências, de outro, cria condições para práticas disciplinares e securitárias de base neoliberal e mundializada que devem ser problematizadas. As mulheres entram na agenda da UNESCO sob o ângulo da segurança ameaçada e da segurança a realizar traduzido em políticas públicas dirigidas a elas e a seus filhos.
\end{abstract}

Palavras-chave: UNESCO; Brasil; mulheres; biopolitica; disciplina.

\section{UNESCO, notes about women and biopower in Brazil}

\begin{abstract}
This article interrogates the practices of the United Nations Educational, Scientific and Cultural Organization (UNESCO) towards brazilian women. Elaborates the Foucault's analytics of racists and utilitarian discourses that promote discipline and securitarian regulations through education and culture. The concern with the violated rights in developing countries named by UNESCO and its designated partners, constitutes an important bulkhead to violence. However, guidelines and practices recommended by this multilateral Organization although potencially capable of producing specific improvements in the lives of some women, update neoliberal biopolitics justified by humanitarian and universalizing principles. Women are on UNESCO'S agenda from the perspective of threatened security and security, translated into public policies aimed at them and their children.
\end{abstract}

Keywords: UNESCO; Brazil; women; biopolitics; discipline.

A preocupação mais incisiva da Organização das Nações Unidas para a Educação, a Ciência e a Cultura (UNESCO) é com a construção da cultura de paz, da difusão do conhecimento, a invenção de novas tecnologias, o compartilhamento de informação, a valorização cultural e dos patrimônios materiais e imateriais, com a preservação da memória de um povo e a prevenção de guerras e violências em função das disputas racistas e de discriminações variadas pelo controle dos pertencimentos sociais e culturais e pela produção do conhecimento e os efeitos da mesma nas relações entre os grupos e povos, em contextos locais, regionais, nacionais e mundiais.

Com o fim de promover uma cultura de paz por meio das condições sociais e econômicas, a UNESCO tem articulado um conjunto de práticas, voltada ao Brasil, específicas ao cotidiano das mulheres. Esse organismo multilateral foi criado em 1946 com a finalidade de evitar guerras, situações de violência, promover a educação, a ciência e a cultura com a utilidade de fomento à paz e à segurança mundiais. Os órgãos das Nações Unidas (ONU), como é o caso da UNESCO, atuam em conjunto e buscam apoio em outras agências internacionais que aumentem a legitimidade e o financiamento das intervenções do Sistema Nações Unidas onde quer que ele atue.

\footnotetext{
^Endereço para correspondência: Universidade Federal do Pará, Instituto de filosofia e Ciências Humanas. Rua Augusto Corrêa, 01 PPGP-IFCH/UFPA - Guama - Belém, PA - Brasil. CEP: 66075110.E-mail: flavazevedo@bol.com.br, dolorescristinagomesgalindo@gmail.com,marildacastelar@gmail.com, lpassarinho28@gmail.com, thaisnogueira_@hotmail.com,pedropiani@yahoo.com.br.
}

A UNESCO faz parte dos dispositivos mundializados de governamentalidade característicos das biopolíticas do pós-guerra que visam ao mesmo tempo garantir a ordem global e a ordem nacional: governar mundialmente sem afetar as soberanias nacionais ou garantir as soberanias nacionais nos contextos de guerra como é o caso das nomeadas democracias, emergentes no mundo árabe.

A pauta da UNESCO, assim como os demais organismos multilaterais do pós-guerra é pactuada e constituída em fóruns variados e, de modo geral, registrada em documentos, assinados pelos países integrantes da ONU, em especial, de 190 Estados, que ratificam grande parte das declarações, pactos, relatórios, ações diversas dos órgãos ligados às Nações Unidas. Como há disputas para que as decisões sejam tomadas e entram em cena jogos de saber e poder para efetuar ou não os consensos e discordâncias que podem ocorrer de diferentes formas e sustentar ou boicotar as conferências, relatórios e declarações forjados pelas Nações Unidas. Trata-se de rivalidades e composições diplomáticas e que têm efeitos no plano das relações internacionais políticas, culturais, econômicas, sociais, religiosas, históricas, ecológicas, subjetivas e geográficas.

Cabe aos assessores nacionais garantir a tradução das políticas globais de governança, formuladas como metas, aos 195 estados nacionais que integram o corpo de países-membros. Nesta maneira de conduzir que articula metas globais e objetivos nacionais, os assessores deste organismo passam a efetuar uma prescrição intensiva ao 
Estado governamentalizado brasileiro e aos equipamentos e instituições correlatas não estatais também locais, regionais e nacionais. Para Foucault (1979, p. 291-292), governamentalidade é:

[...] o conjunto constituído pelas instituições, procedimentos, análises e reflexões, cálculos e táticas que permitem exercer essa forma bastante específica e complexa de poder, que tem por alvo a população, como forma principal de saber a economia política e por instrumentos técnicos essenciais os dispositivos de segurança.

A UNESCO foi criada para atuar nas nações "devastadas" pela guerra, mas passou a direcionar suas ações para as nações que não tinham vivido diretamente os conflitos das grandes guerras. As ações no Brasil foram iniciadas, imediatamente após a fundação da UNESCO, que passou a se articular aos órgãos governamentais e não governamentais para formular, debater e financiar políticas públicas estatais ou não voltadas para todos os segmentos sociais.

Foram criados escritórios da UNESCO, no Brasil, em 1972, o que permitiu uma atuação mais intensiva desse organismo no país. Até esta data havia apenas uma representação, iniciada em 1964 e o escritório de Cooperação Científica, criado ainda na década 1940 tendo sido transferido, posteriormente para o Uruguai. Entre os anos de 1940 e 1960, a UNESCO atuou no Brasil, sobretudo, no financiamento a projetos de pesquisa como, por exemplo, o inventário sobre preconceito e discriminação racial conduzido na década de 1950.

A partir da segunda metade da década de oitenta, do século XX, a UNESCO foi se deslocando de uma posição de parceira e orientadora para uma postura mais propositiva e interventiva, o que aparece nos documentos como uma urgência de ação que seja ao mesmo tempo normalizadora (norma, um operador disciplinar) e reguladora (regulação, um operador dos dispositivos de segurança).

Torna-se urgente superar os mitos, passar para a ação, unir esforços, e enfrentar a pobreza e a iniquidade com um investimento social sustentado, administrado com critérios avançados de gerenciamento social, e projetado para potencializar as pessoas, o principal recurso e o fim último de toda sociedade democrática (UNESCO, 2003, p. 152).

Apoiando-se nas práticas de governo voltadas aos núcleos familiares característica dos projetos de higiene e saúde que adquiriram vigor no oitocentismo, a UNESCO vai recortando os setores da sociedade brasileira para propor políticas de educação, ciência e cultura. Também vai relacionando estas propostas com outras de diversas áreas sempre mantendo como pano de fundo homogêneo a produção de uma família considerada articulada e saudável a figurar como um direito:

A família transforma-se no espaço onde as crianças desenvolvem sua inteligência emocional e capacidade crítico-criativa, e forma hábitos de saúde preventiva. Da mesma forma, ela surge nitidamente como a principal estrutura de prevenção da delinqüência. $O$ papel que ela pode desempenhar no campo moral é fundamental Diversas pesquisas comparativas revelam as estreitas relações existentes entre a delinqüência juvenil e famílias desarticuladas. [...] Como romper com esse círculo e resgatar o imenso potencial da família? Diferentemente do que acontece na América Latina, em alguns países mais avançados do mundo existem, na atualidade, vigorosas políticas de proteção direta á família. Enxerga-se a família como um direito essencial, como um dos sustentáculos de um tecido social sadio, e uma base estratégica para o desenvolvimento econômico (UNESCO, 2003, p. 40-41).

Segundo a UNESCO suas ações no Brasil encontramse divididas em seis grandes áreas, sendo elas: Educação (governança educacional, educação inclusiva, educação preventiva em HIV/Aids), Ciências Naturais (Meio Ambiente, Ciência e Tecnologia), Ciências Humanas e Sociais (Transformação Social, Direitos Humanos, Segurança Humana e Paz), Cultura (Diversidade Cultural, Patrimônio Mundial, Cultura e Desenvolvimento), Comunicação e Informação (Liberdade de expressão, Acesso à informação, Uso de TICS e Educação) e, por fim, Temas especiais definidos como Prevenção e violência nas entre jovens, educação para o desenvolvimento sustentável e relações étnico-raciais (KOICHIRO, 2002)

Num entrecruzamento das áreas de atuação, a educação é vista como investimento econômico que propicia grande retorno e reduz a pobreza, para a UNESCO (2003), o que aponta para um pensamento utilitarista deste organismo. Ora, a defesa do aumento e do retorno de mulheres ao estudo é uma preocupação maior com a segurança e com a economia política do que com os direitos das mesmas a acessar a educação e a cultura.

A UNESCO $(2001,2003)$ vincula falta de estudos com pobreza, iniquidade, falta de trabalho, fragmentação da família e violência. Também relaciona de maneira causal baixa escolaridade com a chefia de mulheres de famílias desfavorecidas e vincula esta situação a uma provável repercussão nos filhos destas mulheres, em especial, a de que eles se tornarão para a UNESCO, delinquentes juvenis e perigo social, o que assinala uma lógica virtual de risco/perigo racista que atravessa esse órgão.

A desigualdade ocasiona efeitos danosos para a deterioração da família. Os estudos indicam que atualmente quase $30 \%$ das famílias da região têm apenas a mãe a cargo do lar. Na sua maioria, trata-se de mães pobres. As graves dificuldades de subsistência financeira fragmentaram a família (UNESCO, 2003, p. 35).

O número de lares onde o único chefe de família é a mãe tem crescido assustadoramente. $\mathrm{O}$ número de crianças que são levadas pelas suas famílias ao trabalho, ou que são realmente forçadas a tomar essa iniciativa para sua subsistência, tem aumentado (UNESCO, 2003, p. 38).

A noção de capital humano é usada para calcular os impactos da escolarização das mulheres na economia de um país e no campo do investimento empresarial da vida. O conhecimento difundido pelos equipamentos educativos é proposto pelos assessores da UNESCO como capital a ser comercializado, trocado, usado, apropriado, vendido, consumido, instrumentalizado utilitariamente em espaços, tempos e aspectos da gestão 
das populações e gerar renda, sobretudo, quando as famílias são chefiadas por mulheres, na opinião dos que redigem os documentos deste organismo:

De fato, o desenvolvimento social fortalece o capital humano, potencializa o capital social e gera estabilidade política - bases essenciais para um crescimento sadio e sustentado. [...] O capital social e a cultura são componenteschave dessas interações. As pessoas, as famílias os grupos são essencialmente capital social e cultural: são portadores de atitudes de cooperação, valores, tradições, visões da realidade que constituem a sua própria identidade. Se isso for ignorado, afastado, deteriorado, capacidades importantes aplicáveis ao desenvolvimento serão inutilizadas, e surgirão resistências poderosas. Pelo contrário, se reconhecermos e explorarmos, valorizarmos e potencializarmos a sua contribuição, ela poderá ser muito relevante e propiciar círculos virtuosos com as outras dimensões do desenvolvimento (UNESCO, 2008, p. 48-50).

De acordo com Foucault (2008b), a ideia de capital humano nasce como suporte de uma sociedade empresarial, após a Segunda Guerra Mundial, no liberalismo norte-americano, na Escola de Chicago e se torna central no mercado neoliberal, das últimas três décadas, de maneira generalizada, em quase todos os países. Passa a ser atrelada ao chamado capital social, cultural, relacional e de recursos naturais, em que todos estes aspectos e situações passam a ser vistas como propiciadoras de renda e de lucro ou não na medida em que são agenciadas por um grupo, região, país e continentes e até mesmo em escala mundial.

A política de redução de pobreza é atrelada à mobilização e investimento de todos estes capitais e a mulher, na família, se torna um alvo privilegiado de governo dos filhos e de apoio ao projeto de sociedade investidora e empresarial. É como ela fosse convidada a ser uma mediadora das práticas neoliberais, operando a transição da vida pública para a privada. Já no século XIX para a família, como bem mostra Donzelot (1986, p. 6), dirigindo-se a manutenção de um Estado liberal por meio da filantropia e de práticas médico-higienistas em dispositivos de polícia:

Num certo sentido, a família passa a ser, pela poupança, ponto de apoio para fazer refluir para ela os indivíduos levados, por seu desregramento, a interpelarem o Estado como instância responsável politicamente por sua subsistência e por seu bem-estar. Num outro sentido, ela se transforma em alvo assumindo as queixas que provinham dos indivíduos contra o arbítrio familiar, o que permite torná-los agentes recondutores das normas estatais na esfera privada. De modo que se poderá tentar compreender a liberalização e a revalorização da família, que irão se desenvolver no final do século XIX, não como o triunfo da modernidade, a mutação profunda das sensibilidades, mas sim como o resultado estratégico da acoplagem dessas duas táticas filantrópicas.
A influência positiva de um componente fundamental do capital social - a família -, em numerosos aspectos, tem sido verificada por várias pesquisas recentes. Quanto maior a solidez desse capital social básico; melhores os resultados e vice-versa (UNESCO, 2008, p. 57).

Há uma nítida hierarquização entre boas e más práticas sexuais e reprodutivas baseada no sistema de sexo/ gênero binário e normativo que busca produzir mulheres domesticadas. É nessa direção que para os especialistas da UNESCO (2001, 2003), a violência figura como resultado de problemas econômicos, do sexo não conjugado a matrimônios heterossexuais, privação cultural e causalmente ligada ao acontecimento baixa escolaridade.

O número de filhos extraconjugais também tem crescido. Da mesma forma, segundo estudos recentes, a pobreza exerce influência significativa sobre o aumento do número de mães adolescentes. $\mathrm{O}$ estresse socioeconômico é um dos elementos que está tendo efeitos sobre um problema que só vem intensificando-se: o da violência doméstica. Ela causa sérios danos às crianças. Um estudo recente, realizado na Nicarágua, detectou que filhos de famílias que sofrem de violência intrafamiliar são hospitalizados com maior frequência, apresentam maior taxa de repetência nas escolas e, em média, abandonam os estudos aos 09 anos de idade (BID, 1997). Por sua vez, aqueles que sofrem violência doméstica nos seus lares tendem a repeti-las depois nas suas próprias famílias (UNESCO, 2003, p. 39).

Diante dos multiplicáveis indicadores que associam a vida das mulheres aos chamados ciclos de reprodução da violência produzidos pelo órgão e outras instâncias a exemplo do Banco Mundial, a UNESCO defende a educação das mulheres segmentando-as em campesinas, indígenas, negras, quilombolas, ribeirinhas, adultas que pararam de estudar sem finalizar o ensino fundamental. Mundialização e regionalização formam planos que se articulam com fissuras e a UNESCO, assim, demanda do Brasil políticas de assistência social complementares de renda e de incentivo para que estas mulheres consigam estudar de maneira a reduzir as "carências do lar":

No campo educacional, é preciso abrir um amplo leque de políticas para quebrar a marginalidade das mulheres pobres. Nos centros urbanos, é preciso apoio especial às meninas pobres para que completem os estudos. São necessários programas de ataque às carências básicas do lar que levam ao abandono escolar, bem como a criação de incentivos positivos para que as famílias apoiem a escolarização das meninas [...] (UNESCO, 2003, p. 136).

Os indicadores relacionados às mulheres para a UNESCO, tais como a gravidez na adolescência, abandono da escola, repetência, violência, hospitalização no parto, nutrição dos filhos, ensino dos filhos pequenos, organização e higiene da casa, amamentação entre outros são computados como estratégicos para reduzir a pobreza, produzir segurança e defender a sociedade de riscos e perigos futuros. Os documentos periodizam a vida em termos ora difusos como meninas e mulheres, ora precisos como é o caso dos programas direcionados à primeira infância. 
Como vimos, estudos pontuais e restritos, feitos por bancos muitas vezes, são recortados pela UNESCO (2003) como evidências abstratas, universais a serem generalizadas para todos os países e contextos. Tal prática nos convoca a uma crítica cuidadosa aos documentos deste órgão e às diretrizes racistas que se pretendem inquestionáveis, legítimas e baseadas em evidências locais através de relatórios que compilam dados e os arranjam sob a forma de indicadores e segmentação populacional. Conjugam-se através de um rol de direitos sempre ampliáveis ao mesmo tempo universalizantes e específicos de tal modo que quase nada pode escapar aos fluxos de controle e mesmo as resistências vão sendo subjugadas sob a forma de uma participação concedida e limitada.

Sem dúvida, como aponta Giacóia Júnior (2008, p. 301), ignorar o papel emancipatório dos direitos humanos seria incorrer num erro histórico, mas atribuir-lhe um valor transcendente é também equívoco por conduzir-nos a pactuar com modalidades contemporâneas de dominação:

Para além de qualquer condenação simplista dos direitos humanos, ignorante do seu papel histórico e de sua inequívoca função emancipatória o vigor de sua crítica leva a pensar numa estratégia para evitar a ingenuidade, teórica e prática, de admitir como armas de resistência - no caso das crises mais agudas que nos acometem - os recursos e instrumentos cuja perempção se torna progressivamente manifesta; ou, o que é ainda pior, de compactuar, uma vez mais candidamente, com modalidades contemporâneas da dominação.

$\mathrm{O}$ uso estratégico dos direitos universalizantes nos dispositivos de controle é um traço das sociedades contemporâneas que humanizam as penas e dirigemse às mulheres e crianças não para supliciar, não para aconselhar e sim para proteger, de preferência, por meio de modalidades participativas que capturam as resistências heterotópicas (PASSETI, 2007).

Nomeamos estas práticas de biopoder porque, de acordo com Michel Foucault (1999a, 1999b, 2008a), as técnicas disciplinares e biopolíticas eram táticas de poder, saber e subjetivação que circulavam, incitavam e eram acionadas como maneiras de governar a vida e os corpos para forjar ampliação da saúde; segurança econômica e política; docilidade política, produtividade e obediência. Os corpos individualizados e coletivos tornavam-se alvos de intervenção contínua, sendo mergulhados em campos de visibilidade.

A disciplina seria um operador sobre o corpo a ser exercitado e treinado de modo contínuo e regular para que suas aptidões sejam aumentadas e suas possibilidades de resistência diminuídas. O paradigma era o da inclusão e não da segregação como tônica da política, apesar do isolamento ocorrer ainda em certas situações consideradas extremas em termos de desvio social.

As "Sociedades Disciplinares" foram constituídas por um triângulo cujos vértices são o poder, o direito e a verdade, em que não havia primazia de um sobre o outro. As relações de poder seriam exercidas por meio de um direito público, sendo fundado na soberania do corpo social e na submissão dos indivíduos à estatização.
O campo de ação dos mecanismos disciplinares era o do controle social dos comportamentos sutis, dos pequenos desvios que não chegam a configurar delitos. A intervenção disciplinar estava ligada à intensificação da observância das regras (FOUCAULT, 1999b).

Podemos notar como os mecanismos disciplinares, cada vez mais, são absorvidos pelo direito.

O juiz torna-se um médico e vice-versa. A sociedade da vigilância quer fundar seu direito sobre a ciência; isso torna possível a suavidade das penas, ou melhor, dos cuidados, das correções, mas estende seu poder de controle, de imposição da norma. Persegue-se o diferente (FOUCAULT, 2003, p. 158).

Trata-se de administrar os menores desvios frente aos modelos de referência, tomados como regras naturais a serem seguidas. E, quanto mais cedo, melhor. É desse modo que os corpos de meninas crianças e adolescentes são capturados pelos dispositivos médicos e psicológicos, revestidos de criatividade, valendo-se para tal do uso instrumental das artes e da cultura por parte de uma sociedade civil, que difusamente representaria a população:

À ação pública, mediante políticas agressivas em favor da infância desvalida, deve-se somar uma grande mobilização da sociedade civil, com a colaboração de empresas privadas socialmente responsáveis, de voluntários, de organizações de todo tipo, que podem contribuir para uma execução eficiente das políticas públicas e acrescentar recursos e iniciativas criativas. São notáveis os êxitos alcançados pelo UNICEF e por instituições como Caritas, Fé e Alegria, Casa Aliança entre outras (UNESCO, 2008, p. 103).

Para efetuar estas práticas, um conjunto de tecnologias políticas é materializado: a observação, o registro, o exame, as comparações, as hierarquizações, as classificações de normal e anormal, as sanções normalizadoras, o controle do tempo e dos corpos no espaço. Qualquer impulso criativo deve ser valorizado e por isso entenda-se vinculálo aos fluxos de controle, pois aquilo que escapa às metas não pode ser incluído nos relatórios como aprendem desde cedo os gestores das organizações sem finalidade lucrativa. A cultura tratada como capital e direito instalase como superfície de controle que reafirma a família como instância nuclear da sociedade em uma noção difusa e, portanto, passível de várias adjetivações: cultura de paz, cultura de saúde preventiva etc.

A cultura pode propiciar uma contribuição efetiva à instituição mais fundamental de integração social, que é a família. Pesquisas realizadas nos últimos anos dão conta de que, juntamente com o seu papel afetivo e espiritual decisivo, a família tem consequências muito relevantes em inúmeras outras áreas. Assim, influi fortemente no rendimento educacional das crianças, na formação da criatividade e do espírito crítico, no desenvolvimento da inteligência emocional, na aquisição de uma cultura de saúde preventiva. Ao mesmo tempo, é uma das principais redes de proteção social e o quadro primário fundamental da integração social (UNESCO, 2008, p. 87).

O tempo foi capitalizado e não poderia ser mais perdido, mas cuidadosamente aproveitado na expansão de habilidades e produção de lucro. Ele deve ser 
administrado para que se torne cada vez mais produtivo e útil. Juntamente com o tempo, o governo pela vigilância hierárquica também entra em composição neste mecanismo disciplinar, que opera por meio da observação contínua e da anotação dos atos em um exercício de escrita, de captura do cotidiano em discurso, nos relatórios e tabelas estatísticas.

É essa compilação infinita das pequenas transgressões que permite que se faça uma história minúscula das desgraças, das mínimas desordens de certos grupos (FOUCAULT, 1999a). Imanente à observação, funciona a sanção normalizadora. Punir e recompensar os comportamentos a partir da contabilização dos comportamentos, distribuídos de acordo com a proximidade e o afastamento de um modelo ideal, ou seja, de uma média. A lógica da sanção é a de uma extensão dos mecanismos judiciários para todas as instâncias da vida. Todos os espaços disparam julgamentos dos comportamentos e correlatamente, punições e/ou recompensas (FOUCAULT, 1999b).

O exame é uma técnica que combina a vigilância hierárquica e a sanção normalizadora. $\mathrm{O}$ exame impõe uma visibilidade constante aos corpos, objetivando-os. As avaliações, as medições nos acompanham pelos espaços em que circulamos durante toda a nossa existência. Somos avaliados em verdade e avaliamos os outros, quadriculando os modos de viver em tabelas quantitativas e números analisados para formulação e execução de políticas de gestão dos corpos em nome da saúde, da economia, da educação, da justiça e da segurança.

Desta forma, gerir o detalhe é a tônica da sociedade disciplinar. Nesta empreitada, nasce uma utilização crescente do manejo de táticas de poder para ordenar as multiplicidades pelas técnicas disciplinares que agem muito pela incitação de certos comportamentos dirigidos ao aumento da produtividade com docilidade política. Além das estratégias disciplinares que individualizam os corpos, Foucault $(1988,2010)$ cartografou outra tecnologia de poder, que ele denominou de biopolítica governo da vida, governo das populações.

A biopolítica é correlata à disciplina, no entanto, produz totalizações, ou seja, estabelecendo comparações dos indivíduos frente a um modelo de referência grupal e foi descrita por Foucault (1988) como prática de produção de seguridade e saúde, aparecendo por volta da metade do século XVIII, com a emergência do capitalismo e dos Estados modernos. E, para governá-los, é preciso, como diz Foucault (1979, p. 284):

Dispor as coisas, isto é, utilizar mais táticas do que leis, ou utilizar ao máximo as leis como táticas. [...] a finalidade do governo está nas coisas que ele dirige, na intensificação dos processos que ele dirige e os instrumentos do governo, em vez de serem constituídos por leis, são táticas diversas.

Entre essas táticas, poderíamos situar a emergência da Economia enquanto uma ciência do governo, uma disposição dos problemas por meio de um cálculo. Os deslocamentos da população produziriam efeitos econômicos e, para poder quantificá-los, a estatística auxiliou juntamente com a economia política, a geografia e a ciência política, a medicina social e a demografia, sendo que o projeto de gestão pública da família, da mulher e da infância tornou-se alvo de prescrições, de campanhas, de uma intensa instrumentalização, enfim, de gestão dos corpos (FOUCAULT, 1979).

Dessa forma, para governar era preciso conhecer, coletar informações, gerar saberes sobre a população, tomar o homem como objeto através de disciplinas como as Ciências Humanas. Enfim, produzir tecnologias para que o Estado operasse eficientemente seu projeto de racionalização política, justificado pela ideia de que a intervenção estatal se dava em função do bem-estar da sociedade, da promoção da felicidade das pessoas, operando através de uma ética utilitária racional (DREYFUS; RABINOW, 1995). Ewald (1993, p. 124) a define como uma medida, uma realidade política, uma regra que vale para toda uma sociedade. Ele esclarece:

[...] A medida comum é uma realidade eminentemente política. É aquilo a partir do qual um grupo se institui como sociedade, aquilo que define os seus códigos, que a pacifica e lhe fornece os instrumentos da sua regulação. [...] Sendo da ordem técnica, as práticas da medida comum são susceptíveis de descrição positiva. Nelas vêm articular-se regimes de saber e dispositivos materiais. Entendida como um estudo das práticas da medida, à filosofia política caberia pensar como é que, através de que lutas e segundo que processos, técnicas de saber e de poder vêm a produzir algo como uma regra ou um conjunto de regras que hão de valer para uma sociedade dada e para um certo período da sua história, como código comum, princípio de federação e de associação.

Mulheres seriam, então, disciplinadas pela escola e pela cultura, explicadas pela ciência e analisadas como parte de engrenagens de poder e de saber que podem subjetivá-las de certa maneira com fins utilitaristas e instrumentais. Elas também podem ser tomadas como uma população decomposta em indicadores de gestão da vida, separadas por meio de fatores de riscos e perigos, calculados biopoliticamente com impactos econômicos e políticos e, assim, governados preventivamente em nome da segurança e cidadania internacionais. Identidades pessoais e indicadores de desenvolvimento mundiais são coadunados: "A busca do desenvolvimento puramente econômico ignora o desenvolvimento da identidade pessoal, que se encontra no cerne de todo projeto educacional viável" (UNESCO, 1997, p. 216).

Nosso propósito é mostrar a todos como a cultura forja todo nosso pensamento, nossa imaginação e nosso comportamento. Ela é, ao mesmo tempo, o veículo da transmissão do comportamento social (UNESCO, 1997, p. 16).

A UNESCO pode contribuir muito, através da educação, para a abertura dos espíritos, aos deveres da solidariedade internacional. Agora que as organizações internacionais e as nações se preparam para os grandes desafios do século XXI a cidadania mundial continua a ser um conceito muito afastado das realidades e percepções concretas. A aldeia global é, contudo, o nosso horizonte à medida que as interdependências se multiplicam e que os problemas se mundializam. (UNESCO, 2006, p. 207). 
As práticas da UNESCO podem ser pensadas neste quadro analítico porque propõem disciplina e gestão da vida das mulheres pela educação, pela ciência e pela cultura como dispositivo de criação da paz mundial e da segurança global, tanto econômica quanto política. Énesse enquadre, por exemplo, que o direito ao desenvolvimento que tem como um dos seus principais expoentes Amartia Sen se torna uma bandeira dos recentes programas e projetos dirigidos às mulheres e crianças.

Para Sen, a preocupação pelo ser humano concreto deve alimentar as análises econômicas de forma permanente. [...] Na concepção de Sen, a obtenção de um progresso econômico tem a ver com critérios que superam as visões convencionais. O desenvolvimento social é peça-chave para o crescimento econômico. As condições de nutrição, saúde e educação da população de um país terão forte influência sobre o desenvolvimento. Como hoje é admitido, o capital humano é fundamental (UNESCO, 2003, p. 186-187).

Para os assessores da UNESCO, há uma relação entre baixa escolaridade e violência, pouca escolaridade e gravidez na adolescência, anos de estudo e duração dos vínculos familiares, desenvolvimento de um país e indicadores das condições de vida das mulheres e entre pobreza e mulheres com poucos anos de estudo. Para a UNESCO há ainda uma relação causal entre número de filhos e escolarização das mulheres adultas, infecção por doenças virais graves e baixa escolarização das mulheres e, finalmente, entre a mulher chefe de família e filhos potencialmente criminosos.

A UNESCO (2001, 2002, 2008) visa o sexo higienizado e demograficamente calculado, no interior do casamento monogâmico e planejado com valores liberais e de acordo com os preceitos dos saberes normalizantes das condutas do segmento mulher como recorte da população a ser biopoliticamente cuidada e governada por meio da gestão de riscos, da estatística com a matemática probabilística: mulher que organiza e limpa a casa, cuida dos alimentos, vestes e vacinação, que zela por amamentar no peito e ter um parto normal, que regula seu ciclo menstrual e usa contraceptivos para que a gravidez fosse prevenida.

Nesse enquadre, a escola e a cultura integram os dispositivos que disciplinam os corpos de mulheres e podem forjar famílias planejadas, mulheres trabalhadoras dóceis, produtivas mães, cuidadosas esposas regradas e aplicadas à família e à defesa social, participativas cidadãs controladas por médicos e pedagogos com seus manuais de saber-poder, formam ainda mulheres que controlam a política e a sociedade do contrato social, na esfera da disciplina para a ordem e o progresso do Estado Democrático de Direito liberal brasileiro. As mulheres são as guardiãs das crianças:

De acordo com os dados da ONU, meio milhão de parturientes morrem cada ano ao dar à luz - mais de $98 \%$ delas nos países em desenvolvimento. Por outro lado, as mulheres constituem a linha avançada na luta pela defesa da vida das crianças, o que, nas condições desfavoráveis impostas pela pobreza, representa uma carga muito pesada (UNESCO, 2008, p. 168).
As mulheres entram na agenda da UNESCO sob o ângulo da segurança ameaçada e da segurança a realizar traduzido em políticas públicas dirigidas a elas e a seus filhos. Foram reunidos equipamentos, leis, relatórios, universidades, instâncias supranacionais, ministérios, secretarias estaduais, bancos, fundações, institutos, ONGs e igrejas em prol da proteção e controle dos corpos de mulheres e das crianças em termos disciplinares e biopolíticos numa governança global.

Provavelmente o parâmetro mais importante para avaliar se uma economia é bem-sucedida não tem a ver com as medidas econômicas convencionais, mas é o que é feito pelas crianças - na medida em que a sociedade lhes garante os direitos indiscutíveis indicados pela ética mais fundamental e pelas constituições democráticas. Muitos países da América Latina estão longe de serem aprovados neste quesito (UNESCO, 2008, p. 102).

É mister traçar os diagramas que, ligando os dispositivos médico-higienistas e filantrópicos característicos do policiamento das famílias à defesa universalizante dos direitos humanos, nutrem as políticas de governamentalização neoliberal da vida pelos organismos multilateriais. A perspectiva de equidade de gênero para a UNESCO era vinculada aos corpos das mulheres, em especial.

A biopolítica com a disciplina foi chamada por Foucault (2008b) de biopoder. No livro História da Sexualidade I (FOUCAULT, 1988), uma analítica do poder saber foi realizada especificamente na esfera de pensar como os corpos das mulheres eram alvo de práticas de governo ligadas à procriação, ao cuidado com os filhos e com o casamento, na educação utilitarista e baseada na economia política liberal. A UNESCO, nesse sentido, organiza biopolítica e disciplina para governar mulheres, no Brasil, na medida em que propõe um lugar diferenciado às mães de controle da família e colaboração com o Estado, na educação dos filhos e na vigilância do cônjuge, na dimensão da gerência da sexualidade como dispositivo de governo da população e de submissão individual das condutas às normas sociais.

\section{Conclusão}

$\mathrm{O}$ artigo possibilitou pensar o governo das mulheres pela UNESCO, no Brasil, a partir de algumas práticas governamentalizadas, no contemporâneo. A gestão da vida visava criar uma defesa social de forma racista de segmentos da população, biologicamente recortada como espécie, e a disciplina focaria o corpo minuciosamente para torná-lo adestrado e individualizado, dócil e produtivo com tecnologias de controle do tempo, do espaço, vigilância hierárquica, exames permanentes e sanções normalizadoras. As mulheres seriam governamentalizadas, pela biopolítica e pela disciplina, na perspectiva de um governo das condutas voltado à paz para a UNESCO.

A disciplina ocorre na condução minuciosa das mulheres pelas cartilhas da UNESCO, pelas prescrições educativas de como devem viver, sentir, agir, se relacionar e pensar, demarcadas pelas regras de sociabilidade do 
que seria mulher para os assessores desse órgão e do que esses especialistas esperam dos comportamentos e mínimas ações cotidianas das mulheres, em exercício da maternidade, do casamento e do cuidado de suas casas e família. Em termos da biopolítica, as mulheres são convocadas a zela pela procriação, pela existência de uma espécie reproduzida e bem educada, segundo o modelo de um Estado de Direito e sob o verniz de uma racionalidade democrática da lei e da ordem social securitária. Assim, o biopoder seria um mecanismo de governo das mulheres, de acordo com a UNESCO.

\section{Referências}

DONZELOT, J. Polícia das famílias. Rio de Janeiro: Graal, 1986.

DREYFUS, H.; RABINOW, P. Michel Foucault-uma trajetória filosófica: para além do estruturalismo e da hermenêutica. Rio de Janeiro: Forense Universitária, 1995.

EWALD, F. Foucault, a Norma e o Direito. Lisboa: Vega, 1993.

FOUCAULT, M. Microfisica do poder. Rio de Janeiro: Graal, 1979.

FOUCAULT, M. História da sexualidade: a vontade de saber. Rio de Janeiro: Graal, 1988. v. 1.

FOUCAULT, M. Vigiar e Punir: a história da violência nas prisões. Petrópolis, RJ: Vozes, 1999a.

FOUCAULT, M Em defesa da sociedade. São Paulo: Martins Fontes, 1999b.

FOUCAULT, M. Estratégia, poder-saber. Rio de Janeiro: Forense Universitária, 2003. Coleção Ditos \& Escritos, v. 4.

FOUCAULT, M. O nascimento da biopolítica. São Paulo: Martins Fontes, 2008a.

FOUCAULT, M. Segurança, território e população. São Paulo: Martins Fontes, 2008b.

FOUCAULT, M. A hermenêutica do sujeito. São Paulo: Martins Fontes, 2010.

GIACÓIA JÚNIOR, O. Sobre direitos humanos na era da biopolítica. Kriterion: Revista de Filosofia, Belo Horizonte, v. 49, n. 118 , p. 267-308, dec. 2008. Cross ${ }^{\text {Ref. }}$

KOICHIRO, M. A UNESCO e os desafios do novo século. Brasília: UNESCO, 2002.

ORGANIZAÇÃO DAS NAÇÕES UNIDAS PARA A EDUCAÇÃO, A CIÊNCIA E A CULTURA. Nossa diversidade criadora: Relatório da Comissão Mundial de Cultura e Desenvolvimento. Brasília: UNESCO, 1997.

ORGANIZAÇÃO DAS NAÇÕES UNIDAS PARA A EDUCAÇÃO, A CIÊNCIA E A CULTURA. Cultivando vida, desarmando violências: experiência em educação, cultura, lazer, esporte e cidadania com jovens em situação de pobreza. Brasília: UNESCO, 2001.

ORGANIZAÇÃO DAS NAÇÕES UNIDAS PARA A EDUCAÇÃO, A CIÊNCIA E A CULTURA. Construção $e$ identidade: as ideias da UNESCO no Brasil. Brasília: Jorge Werthein/UNESCO, 2002.

ORGANIZAÇÃO DAS NAÇÕES UNIDAS PARA A EDUCAÇÃO, A CIÊNCIA E A CULTURA. Por uma economia com face mais humana. Brasília: UNESCO, 2003.
ORGANIZAÇÃO DAS NAÇÕES UNIDAS PARA A EDUCAÇÃO, A CIÊNCIA E A CULTURA. Relatório Jacques Delors. Educação para o século XXI: um tesouro a descobrir. Brasília: Cortez/MEC/UNESCO, 2006.

ORGANIZAÇÃO DAS NAÇÕES UNIDAS PARA A EDUCAÇÃO, A CIÊNCIA E A CULTURA. Mais ética, mais desenvolvimento. Brasília: UNESCO, 2008.

PASSETTI, E. Direitos humanos, sociedade de controle e a criança criminosa. In: COMISSÃO DE DIREITOS HUMANOS/CRP-RJ. (Org.). Direitos humanos? O que temos a ver com isso? Rio de Janeiro: CRP-RJ, 2007. v. 1, p. 63-81.

Recebido em: 7 de dezembro de 2012 Aceito em: 5 de novembro de 2015 